\title{
ASTRONOMICAL CALIBRATION OF THE FAMENNIAN (UPPER DEVONIAN) TIME SCALE
}

PAS, Damien, Department of Atmospheric, Oceanic and Earth Sciences, George Mason University, Fairfax, VA 22030, HINNOV, Linda A., Atmospheric, Oceanic and Earth Sciences, George Mason University, Fairfax, VA 22030, DAY, James, Geography \& Geology, Illinois State University, Normal, IL 61790-4400, KODAMA, Kenneth P., Earth and Environmental Sciences Dept, Lehigh Univ, 31 Williams Dr, Bethlehem, PA 18015, SINNESAEL, Matthias, Analytical Environmental and Geo-Chemistry (AMGC), Vrije Universiteit Brussel, Brussels, 1050, Belgium and LIU, Wei, School of Ocean Sciences, China University of Geosciences, Beijing, Beijing, 100083, China, dpas@gmu.edu

The Late Devonian was affected by major, irreversible changes including two of the most severe biodiversity crises in Earth's history, the so-called Kellwasser and Hangenberg Events (respectively near the Frasnian - Famennian (F-F) and the Devonian - Carboniferous (D-C) boundaries). Currently, hypotheses for the Late Devonian extinctions include sea-level fluctuations and regression, climate cooling, ocean anoxia, massive volcanism and/or bolide impact. Unfortunately, testing these hypotheses is impaired by a lack of sufficient temporal resolution in paleobiological, tectonic and proxy climate records. Recent advances in astronomical calibration have improved the accuracy of the Frasnian time scale and part of the Famennian. However, the time duration of the Famennian Stage remains poorly constrained. During the Late Devonian, an epieric sea in North-America mid-continent occupied the Illinois Basin where a complete Late Frasnian - Early Carboniferous succession of deep-shelf deposits was archived. A record of this sequence is captured in three overlapping cores (H-30, Sullivan Slough and H-32). The H-30 core section spans the F-F boundary; the Sullivan Slough section spans almost all of the Famennian and the H-32 section sampled spans the D-C boundary. To have the best chance of capturing Milankovitch cycles, 2200 rock samples were collected at minimum 5-cm-interval across the entire sequence. Magnetic susceptibility (MS) was measured on each sample and the preservation of climatic information into the signal was verified through geochemical analyses. To estimate the duration of the Famennian stage, we applied multiple spectral techniques and tuned the $M S$ signal using the highly stable $405 \mathrm{k} . \mathrm{y}$. cycle for Sullivan Slough and the obliquity cycle (34.4 k.y.; Waltham, 2015) for the H-30 and H-32 cores. Based on the correlation between the cores and the tuning, we constructed a Famennian astronomical time scale, which indicates a duration of $13.3 \mathrm{~m}$.y. An uncertainty of $\pm 0.5 \mathrm{~m} . \mathrm{y}$. was calculated to assess the errors raising from the stratigraphic position of the F-F and D-C boundaries, and the $405 \mathrm{k} . y$. cycle counting error. Our estimate duration is very close to the GTS-2012 duration (Becker, 2012) interpolated from the high-resolution $(\mathrm{U} / \mathrm{Pb})$ radiometric ages available for the uppermost Devonian.

Abstract ID\#:

306730

Password:

512472

Meeting:

GSA Annual Meeting in Seattle, Washington, USA - 2017

Session Type:

Topical Sessions 
Primary Selection:

T47. Recent Developments in Cyclostratigraphy

Final Session Number:

164

Abstract Title:

ASTRONOMICAL CALIBRATION OF THE FAMENNIAN (UPPER DEVONIAN) TIME

SCALE

Preferred Presentation Format:

Oral

Discipline Categories:

Paleoclimatology/Paleoceanography Stratigraphy

Abstract Submission Fee:

Paid (gsa-2017AM-1756-5541-9519-5859)

Presenting Author

Damien Pas

George Mason University

Department of Atmospheric, Oceanic and Earth Sciences

Fairfax, VA 22030

Phone Number: 5712785031

Email:dpas@gmu.edu

Student? N

Linda A. Hinnov

George Mason University

Atmospheric, Oceanic and Earth Sciences

Fairfax, VA 22030

Phone Number: 4102079928

Email:1hinnov@gmu.edu

Alternate Email: lindahinnov@gmail.com

Student? N

James Day

Illinois State University

Geography \& Geology

Normal, IL 61790-4400

Phone Number: 309-438-8678

Fax Number: 309-438-5310

Email: jeday@ilstu.edu

Student? N

Kenneth P. Kodama

Lehigh Univ

31 Williams Dr

Earth and Environmental Sciences Dept

Bethlehem, PA 18015

Phone Number: 610-758-3663

Email:kpk0@lehigh.edu

Student? N 
Matthias Sinnesael

Vrije Universiteit Brussel

Analytical Environmental and Geo-Chemistry (AMGC)

Brussels, 1050

Belgium

Phone Number: +32-2-6291479

Email: matthias.sinnesael@vub.be

Student? Y

Wei Liu

China University of Geosciences, Beijing

School of Ocean Sciences

Beijing, 100083

China

Phone Number: 571-278-6892

Email:1wgeo90@gmail.com

Student? Y 